\title{
Analysis on Present Condition of Patent Industrialization and Countermeasures
}

\author{
Tan Qinyi ${ }^{1, a}$ \\ ${ }^{1}$ Haining science and Technology Innovation Center, Zhejiang Haining 314400, China \\ a116315433@qq.com
}

Keywords: patent; industrialization; countermeasures

\begin{abstract}
China increases year by year, the quality of patents is not great; the government doesn't invest much, and companies have a few proprietary intellectual property rights; moreover, the innovation capacity in our country is not strong and intermediary services are not sound, which restricts the patent industrialization development in our country greatly. On the basis of making analysis on the present condition of patent industrialization, this paper takes example by the successful experience and model in developed countries and puts forward constructive countermeasures for the patent industrialization in China.
\end{abstract}

\section{Introduction}

The important job to reinforce the proprietary intellectual property rights is to put forward the implementation of patent and industrialization, which is the only way for our country to develop national comprehensive knowledge capability and to enhance knowledge industrialization. Only when the company has its intellectual property with core competence, can it gain the opportunity of survival in cruel competitive environment. Therefore, the construction of patent industrialization and the formation of products with proprietary intellectual property rights help the sustainable development of companies in our country ${ }^{[1]}$.

\section{Concept of patent industrialization}

Patent industrialization refers to a process of patented technology with core value making its relevant products to reach certain scale in the market and to realize industrialization through different channels. Of course, the industrialization that we mentioned means our products not only to survive in the market, but also to bring considerable earnings to companies. Patented technology industrialization usually contains four stages; the first stage is productization, which is so-called testing stage, integrating our patented technology with products for processing and production. The second stage is factorization, which means starting to make mass production for the market; the next stage is serialization, and when new products meet our requirements, mass production begins; the last stage is the real industrialization of patents and fixed technical products with impressive benefits are formed.

\section{Analysis on the present condition of patent industrialization}

As for the analysis on the present condition of patent industrialization in our country, there are mainly two opinions. The first is that patent industrialization in our country has made great progress and achievements and impressive outcomes can be seen both in the application amount of patents every year and in the economic promotion in our country, which can be seen in Figure $1^{[2]}$; the other one is that the development of patent industrialization in our country is not optimistic and even doesn't coordinate with our national economic development. Different conclusions occur in front of the same facts, the reason for which lies in the angle to analyze. The first one makes longitudinal comparison and analysis with the reference to different periods in our country and concludes that patent industrialization in our country has made great achievements. The other one makes 
comparison and analysis with the reference to developed countries and concludes that patent industrialization in our country is not enough. Both opinions are right in respective angles. However, the problem is that which side should be more emphasized in the issues of patent industrialization development for the government and related personnel of patents. The author believes that the second aspect should be paid more attention against the background of global economic integration, which means that we still fall behind developed countries in the aspect of technical innovation. Therefore ,we make specific analysis and study on following aspects.

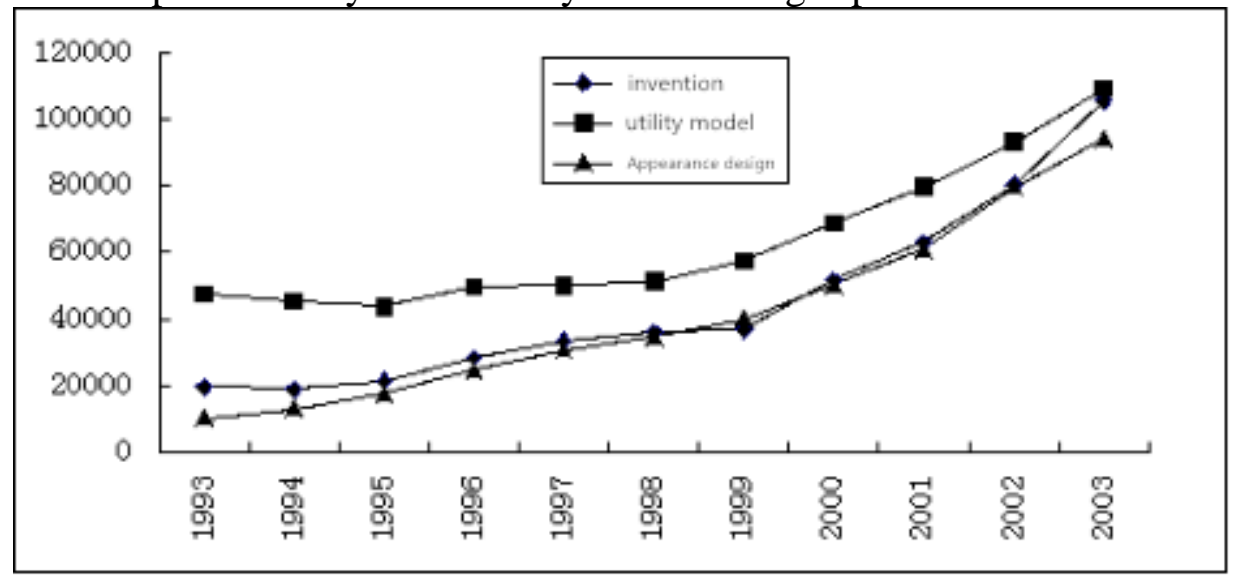

Figure 1. Data of patented invention in the country

(1) Ratio of invention patent application amount: among the patent application accepted in our national intellectual property office, the national patent application occupies absolute advantage in the total quantity, but most is in the aspect of utility model appearance design. As for invention patent, foreign patent application takes larger advantages and the amount gap between domestic and foreign invention patent application has the trend to increase ${ }^{[3]}$.

(2) Ratio of service invention and non-service invention: among the patent application submitted by domestic and foreign clients to national patent bureau, the ratio of service invention and non-service invention has obvious difference: among domestic invention patent application, non-service invention plays the main role and the amount can occupy as much as 70\%; among foreign invention patent application, service invention plays the main role, which can occupy as much as $90 \%$ of the application amount, and during recent years, the ratio is as much as $96.90 \%$. (Refer to Table 1)

Table 1 Ratio of applied and granted amount of service invention and non-service invention

\begin{tabular}{|l|l|l|l|l|l|l|}
\hline Invention patent application & 1986 & 1990 & 1998 & 2001 & 2014 \\
\hline \multirow{3}{*}{ Domestic } & $\begin{array}{l}\text { Service } \\
\text { invention }\end{array}$ & $42 \%$ & $31.80 \%$ & $33.60 \%$ & $49.30 \%$ & $74.20 \%$ \\
\hline $\begin{array}{l}\text { Fon-service } \\
\text { invention }\end{array}$ & $58 \%$ & $68.20 \%$ & $66.40 \%$ & $50.70 \%$ & $25.80 \%$ \\
\hline \multirow{2}{*}{$\begin{array}{l}\text { Service } \\
\text { invention }\end{array}$} & $90.90 \%$ & $92 \%$ & $96 \%$ & $96 \%$ & $96.90 \%$ \\
\hline $\begin{array}{l}\text { Non-service } \\
\text { invention }\end{array}$ & $9.10 \%$ & $8 \%$ & $4 \%$ & $4 \%$ & $3.10 \%$ \\
\hline
\end{tabular}

*Data source: according to data published by state intellectual property office

(3) As for the benefits brought by patents to company, the benefit in patent market is commonly low: according to the ratio of benefit from patent by company every year in our country, nearly $70 \%$ of patents don't bring any benefit from economic market; the ratio of patent gaining benefit of more than 1000 thousand yuan is about $8.4 \%$, and the ratio of patent gaining benefit of more than 50 million yuan is no more than $0.1 \%$.

(4) As for institutional framework, it lacks in professional patent intermediary service institution. On one hand, our country have many technical patents waiting to apply, and on the other hand, there are many people with the intention to invest in proper patent projects, the non-equivalence of information influencing the application of patent technology in products in reality to a great degree. 


\section{Countermeasures for patent industrialization in our country}

Through the analysis on the present condition of patent industrialization, we believe that it is necessary to put forward and promote the development and implementation of patent industrialization, and to support a group of products of proprietary intellectual property rights with great influence and large scale. For various patents, it needs to analyze the development features of their free industrialization model, to choose proper developing form, and to do following three aspects well.

\section{Support and build platform of professional technique service}

The success of patent technology industrialization cannot usually be gained through certain single patent technology. It needs the help of relevant technological means and secondary development of patented technology. Therefore, the construction of relevant matching technology platform is an important means to promote patent industrialization. We should accelerate to cultivate and develop a group of key enterprises and scientific research institutions on the basis of focusing on market core competitiveness. On this basis, we should also integrate various innovative platform and resources to build three kinds of scientific research platforms of our industry, patent and regions through various means ,to form diverse comprehensive development unions of industry-university-research cooperation, and we should make the built innovation platform construction become a rallying point of relevant technical personnel and a highland of patent industrialization ${ }^{[4]}$.

\section{Improve the construction of environment of investment and financing}

In the aspect of improving financing environment, firstly, the government should shoulder its proper responsibilities and increase the investment in patent industrialization. Secondly, special patent fund should be designed to provide certain credit guaranty for company, which can provide preferable capital support in the development of patent afterwards. According to the condition that the author knows, without the credit guaranty of government, the innovative business capital with patent as the main part is usually very little; the loans are difficult to get banks' approval; at this time, if the government makes the guarantee, it can bring confidence for the bank. Through the successful experience of foreign developed countries, the credit guarantee of government has great effect. Relevant data shows that in the patent's enterprise guarantee, government's $1 \%$ support can drive $10 \%$ to $15 \%$ capital in the market to flow to the patent enterprises with innovation ${ }^{[5]}$.

\section{Develop intermediary service institution rapidly}

Patent intermediary institution has important position and function in the whole process of industrialization; especially in the patent development state, the guidance of intermediary service is indispensable. In the process of patent industrialization, the intermediary institution provides analysis, evaluation, promotion, consultation service for present technical market and prepares for the needed capital for patent. During recent years, with the development of social economy and the rise of internet, the trend of network office in intermediary institution is obvious; as for the industrialization in developed countries in the world, the resume of patent database can provide a convenient communication place for various scientific research institutions, which can save social resources greatly and bring great help for the elevation of patent industrialization.

\section{References}

[1] Xing Shengcai. Promote patent implementation and industrialization actively [J]. Invention and Patent, 2005, (11)

[2] Chinese Intellectual Property (2011) [M]. Beijing: Intellectual property publishing house.

[3] Yu Xiaoyu, Cai Li. Industrialization mechanism, key problems and driving strategies of patent technology [J]. Scientific research, 2010.5; 681-689.

[4] Han Xiucheng. American patent policies and its strategies in high-tech industry [J]. Intellectual Property, 2001, (3) 
[5] Lai Hong. Influence of patent literature in company development [J]. Intellectual Property, 2000, (6) 